Jpn. J. Genet. (1991) 66, pp. 461-469

\title{
Somatic reversion of a Xantha-like gene in soybean by fast neutrons and $X$ rays
}

\author{
Tetsuo IтоH and Sohei Kondo \\ Atomic Energy Research Institute, Kinki University, \\ Kowakae, Higashiosaka, Osaka 57\%, Japan
}

(Received 28 May 1991)

\begin{abstract}
The variety T219 of Glycine max (soybean) has a wild-type chlorophyll development gene $Y_{11}$ and its allele $y_{11}$. Seeds from autogamous T219 plants produce dark green $\left(Y_{11} Y_{11}\right)$, light green $\left(Y_{11} y_{11}\right)$ and yellow $\left(y_{11} y_{11}\right)$ seedlings. Upon irradiation of dry seeds with $\mathrm{X}$ rays, the frequency of light-green mosaics on $y_{11} y_{11}$ simple leaves was about twice as high as that of dark-green mosaics on $Y_{11} y_{11}$ simple leaves. For the explanation of the two-fold difference in mutability, we propose that both the light-green and the dark-green mosaics are caused by reversion of $y_{11}$ to $Y_{11}$, as the number of target gene $y_{11}$ per cell in the $y_{11} y_{11}$ tissue is twice that in the $Y_{11} y_{11}$ tissue. Somatic reversion of the $y_{11}$ gene was induced, in either $y_{11} y_{11}$ or $Y_{11} y_{11}$ plants by $14 \mathrm{MeV}$ neutrons and by fission neutrons at a rate about 20 times higher than that by $X$ rays, suggesting that the reversions result from deletion mutations. To explain the occurrence of the reversion by deletions, we assume that the $y_{11}$ gene is a complex gene made of a transposable element inserted at the $Y_{11}$ locus and that the reversion resulted from the deletion of the inserted transposon. The phenotype of the $y_{11}$ gene shares many similarities with those of Xantha genes mapped at several loci in barley and tomato.
\end{abstract}

\section{INTRODUCTION}

Variety T219 of Glycine $\max$ (L.) Merrill (soybean) exhibits incomplete dominance of the chlorophyll development gene $Y_{11}$ over its allele $y_{11}$ so that $Y_{11} Y_{11}$ plants are dark green in color, $Y_{11} y_{11}$ plants are light green and $y_{11} y_{11}$ plants have golden yellow leaves; simple leaves of $Y_{11} y_{11}$ plants are frequently dotted with small spots that are either dark green (resembling leaves of $Y_{11} Y_{11}$ ), yellow (resembling leaves of $y_{11} y_{11}$ ) or twin (composed of a dark green area adjacent to a yellow area similar in size and shape) (Weber and Weiss, 1959; Vig and Paddock, 1968; Vig, 1973a). This strain has been used as a tester for environmental mutagens; $Y_{11} y_{11}$ seeds soaked in water containing mutagenic chemicals produced yellow, dark-green and/or twin spots at high frequencies on simple leaves (Vig, 1975; Fujii, 1981, 1982; Fujii et al., 1983). Mechanisms of twin spots have been extensively studied, leading to the conclusion that the twin spots are caused by somatic crossing over (Vig and Paddock, 1968; Vig, 1973a, 1973b, 1973c, 1974, 1978; Vig et al., 1976). 
After exposure of $y_{11} y_{11}$ and $Y_{11} y_{11}$ seeds to gamma rays or ${ }^{3} \mathrm{H}$ beta rays, light-green spots were produced on simple leaves of $y_{11} y_{11}$ plants at frequencies as high as total frequencies of dark-green, yellow and twin spots on simple $Y_{11} y_{11}$ leaves (Vig, 1974). Vig (1974) and Vig et al. (1976) interpreted that the major cause of the occurrence of light-green spots on $y_{11} y_{11}$ leaves is point mutations. The present paper, however, deals with experimental results supporting the idea that light-green spots appearing on $y_{11} y_{11}$ leaves are caused by deletion of a cryptic transposable element inserted at the $Y_{11}$ locus that partially suppresses the wild-type function of the $Y_{11}$ gene, resulting in the formation of a Xantha-like $y_{11}$ gene.

\section{MATERIALS AND METHODS}

Strain

The strain T219 of Glycine max used was obtained from the late Dr. T. Fujii, National Institute of Genetics; he obtained this strain from Prof. B. K. Vig, University of Nevada. The genotype of this strain is made of the wild-type gene $Y_{11}$ and its allele $y_{11} . \quad Y_{11} Y_{11}$ plants are dark green in color, $Y_{11} y_{11}$ plants are light green and $y_{11} y_{11}$ plants are golden yellow as if almost lacking chlorophyll (Vig, 1973a). Seeds were harvested from autogamous $Y_{11} y_{11}$ plants and stored at about $5^{\circ} \mathrm{C}$ in a refrigerator.

\section{Irradiation and radiation dosimetry}

$\mathrm{X}$-irradiation was carried out with an X-ray generator (Rigaku Denki Co., Osaka) at Radiation Biology Research Center, Kyoto University; which was operated at $250 \mathrm{kVp}$ and $15 \mathrm{~mA}$ with $1 \mathrm{~mm} \mathrm{Al}$ filter. The dose rate used was 1.05 $\mathrm{Gy} / \mathrm{min}$ as measured by a Victoreen chamber.

Irradiation with $14 \mathrm{MeV}$ neutrons was carried out with a neutron generator named OKTAVIAN (Sumita et al., 1982) at Osaka University. It produced monoenergetic $14 \mathrm{MeV}$ neutrons by bombarding a $10 \mathrm{Ci}$ tritium target with 240 $\mathrm{keV}$ deuteron beams; its out put intensity was $2.0 \times 10^{11}$ neutrons/sec. Dishes containing seed samples were placed at distances of 60 to $122 \mathrm{~cm}$ from the tritium target and irradiated for 1 hour. Fluences of $14 \mathrm{MeV}$ neutrons were monitored by thin niobium foils (Oda et al., 1988; Yamamoto et al., 1989) attached to sample dishes. After irradiation, radioactivities of niobium foils were measured to estimate fluences of $14 \mathrm{MeV}$ neutrons given to sample dishes. Doses of contaminated gamma rays were measured by thermoluminescence dosimeters UD-170L (Matsushita Electric Industry Co., Osaka).

Irradiation of seeds with fission neutrons was made using a nuclear reactor in Kinki University. Dose rates of fission neutrons and gamma rays from the reactor were separately measured with a pair of a tissue-equivalent ion chamber and a graphite ion chamber; doses of neutrons and gamma rays given to seed 
samples were also monitored in situ by plastic-nuclear track detectors TS16N (Nagase-Landauer Co., Tokyo) and thermoluminescence dosimeters UD-170L attached to each of the sample containing dishes, as previously described (Yasubuchi et al., 1989).

\section{Observation of somatic mutant mosaics}

Within two hours after the completion of irradiation, seeds were sown on soil in nursery beds; they were kept in a greenhouse at $20-30^{\circ} \mathrm{C}$ for two to three weeks until simple and first compound leaves were formed. In $Y_{11} y_{11}$ seedlings, darkgreen, yellow and twin mosaics were scored on simple leaves whereas in $y_{11} y_{11}$ seedlings, light-green mosaics were scored on simple leaves.

\section{RESULTS AND DISCUSSION}

Factors for conversion of neutron fluence and photon exposure to absorbed doses in tissue of dry soybean seeds

Fluence of fast neutrons, $F$ (neutrons $/ \mathrm{cm}^{2}$ ), and exposure of $\mathrm{X}$ or gamma rays,

Table 1. Fluence-to-dose conversion factor $k_{S T}$ and exposure-to-dose conversion factor $f_{S T}$ for soybean dry seeds

\begin{tabular}{cccccc}
\hline \hline $\begin{array}{l}\text { Neutron } \\
\text { energy } \\
\text { (MeV) }\end{array}$ & $\begin{array}{c}k_{S T}\left(10^{-9}\right. \\
\text { cGy/fluence) }\end{array}$ & $k_{S T} / k_{H T}$ & $\begin{array}{c}\text { Photon } \\
\text { energy } \\
(\mathrm{MeV})\end{array}$ & $f_{S T}$ & $f_{S T} / f_{H T}$ \\
\hline 14 & 5.70 & 0.88 & 1 & 0.886 & 0.92 \\
1.3 & 2.04 & 0.81 & 0.3 & 0.886 & 0.92 \\
1 & 1.91 & 0.78 & 0.15 & 0.874 & 0.91 \\
0.8 & 1.63 & 0.82 & 0.1 & 0.837 & 0.88 \\
0.3 & 1.00 & 0.81 & 0.08 & 0.792 & 0.84 \\
0.1 & 0.518 & 0.81 & 0.06 & 0.694 & 0.74 \\
\hline
\end{tabular}

$k_{S T}=N_{A} \sum_{i}\left(w_{i}[/ \mathrm{g}] / A_{i}\right) \sigma_{i} E_{i}[\mathrm{MeV}$ barns $] / 6.24 \times 10^{7}[\mathrm{MeV} / \mathrm{g}] . \quad$ In this equation, $N_{A}$ is Avogadro's number, $w_{i}$ is the fraction of element $i$ by weight in dry soybean seeds $(7.9 \pm 0.2 \% \mathrm{H}, 47.0 \pm 0.1 \% \mathrm{C}$, $7.0 \pm 0.01 \% \mathrm{~N}, 31.4 \pm 0.2 \% \mathrm{O}$, and $6.7 \pm 0.3 \%$ other elements; measured by Toray Research Center Inc., Siga), $A_{i}$ is the mass number of element $i, \sigma_{i} E_{i}$ is the total kinetic energy transferred from reactions of neutrons with nuclei of element $i$, and the denominator is the $(\mathrm{MeV} / \mathrm{g})$-to-cGy conversion factor. The $\sigma_{i} E_{i}$ values for $14 \mathrm{MeV}$ neutrons were obtained from Randolph (1957), i.e., 4.86 for $\mathrm{H}, 2.99$ for $\mathrm{C}, 3.42$ for $\mathrm{N}, 3.73$ for $\mathrm{O}$. The $k_{S T}$ values for neutrons with energies 0.1 to 1.3 $\mathrm{MeV}$ were calculated using Eq. (2) in the text with the values of kerma factors given in ICRU Report 13 (1969).

$f_{S T}=0.877\left(\mu_{S T} / \mu_{A I R}\right)$. In this equation, $\mu_{S T}=\sum_{i} \mu_{i} w_{i}$ ( $\mu_{i}$ is energy absorption coefficient of element $i$ per $1 \mathrm{~g} / \mathrm{cm}^{2}$ and $w_{i}$ the fraction by weight of element $i$ in tissue of dry soybean seeds) and $\mu_{A I R}$ is energy absorption coefficient of air per $1 \mathrm{~g} / \mathrm{cm}^{2}$. The $\mu_{i}$ and $\mu_{A I R}$ values for photons at various energies used were taken from ICRU Report 10b in 1962 (1964). The spectrum of X rays from the $\mathrm{X}$-ray generator used at $250 \mathrm{kVp}$ was assumed to be similar to that given in Fig. 3h of ICRU Report in 1956 (1957), which gives an average energy of about $100 \mathrm{keV}$. 
$X$, are related to absorbed dose $D$ in the tissue of dry soybean seeds by

$$
D=k_{S T} F ; \mathrm{D}=f_{S T} X,
$$

where $k_{S T}$ is the kerma factor, i.e., the fluence-to-dose conversion factor, for soybean cotyledon tissue and $f_{S T}$ is the exposure-to-dose conversion factor for soybean cotyledon tissue. The $k_{S T}$ and the $f_{S T}$ values are calculated by

$$
k_{S T}=\sum_{i} k_{i}\left(E_{N}\right) w_{i} ; f_{S T}=\sum_{i} f_{i}\left(E_{G}\right) w_{i},
$$

where $k_{i}$ is the kerma factor for neutrons for element $i$ in energy $E_{N}, w_{i}$ is the fraction by weight of element $i$ in the tissue of dry soybean seeds and $f_{i}$ is the R-to-Gy conversion factor for photons with energy $E_{G}$.

For $14 \mathrm{MeV}$ neutrons, we calculated the $k_{S T}$ value using the $k_{i}$ values given by Randolph (1957) and measured $w_{i}$ values as given in Table 1. For dosimetry of fission neutrons from the nuclear reactor, $k_{S T}$ values were calculated at discrete energies as given in Table 1; they vary greatly with changes in $E_{N}$ but the ratio of $k_{S T}$ to $k_{H T}\left(k\right.$ value for human tissue) remains almost constant for different $E_{N}$ values. Dosimetry of the mixed radiation from the Kinki University Reactor was done with paired ion chambers; the dose rate was 0.20 and 0.22 (both in Gy in human tissue per hour) for neutrons and gamma rays, respectively. These numerical values become 0.16 and 0.19 (Gy in dry soybean cotyledon tissue per hour), respectively, when the $k_{S T} / k_{H T}$ values and $f_{S T} / f_{H T}$ values given in Table 1 are used.

Observed frequencies of somatic mosaics on $y_{11} y_{11}$ and $Y_{11} y_{11}$ leaves after irradiation

In Fig. 1, frequencies of light-green mosaics on yellow $y_{11} y_{11}$ simple leaves (Fig. 1A), and those of dark-green mosaics (Fig. 1B) and yellow ones on light green $Y_{11} y_{11}$ simple leaves (Fig. 1C) are plotted against doses of $\mathrm{X}$ rays, $14 \mathrm{MeV}$ neutron- gamma mixed radiation and fission neutron-gamma mixed radiation given to dry soybean seeds.

Frequencies of twin mosaics did not increase appreciably above control levels after irradiation (data not shown).

Comparison of induction rates (/leaf/Gy) by $X$ rays, $14 \mathrm{MeV}$ neutrons and fission neutrons for three types of somatic mutations

Observed frequency-versus-dose curves were approximately linear for the three types of somatic mutations (Fig. 1). Therefore, the data used for Fig. 1 were fitted by the least square method to a linear regression equation

$$
Y=a+b D \text {, }
$$

where $Y$ is frequency of mosaics per leaf after irradiation with dose $D$ (Gy in dry 

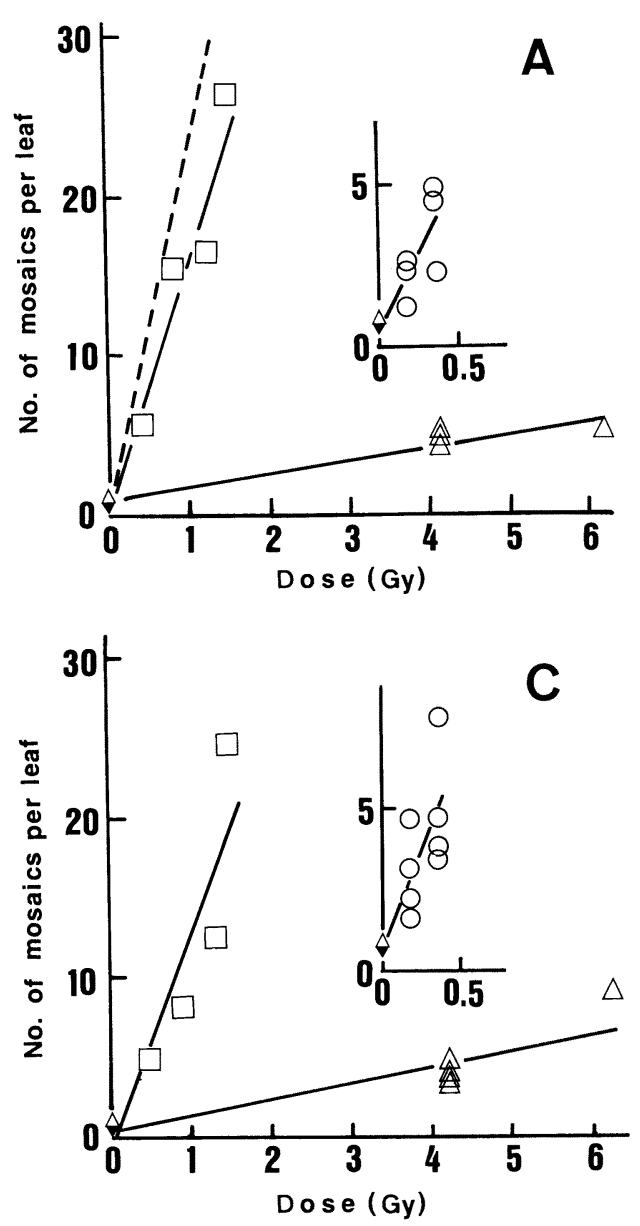

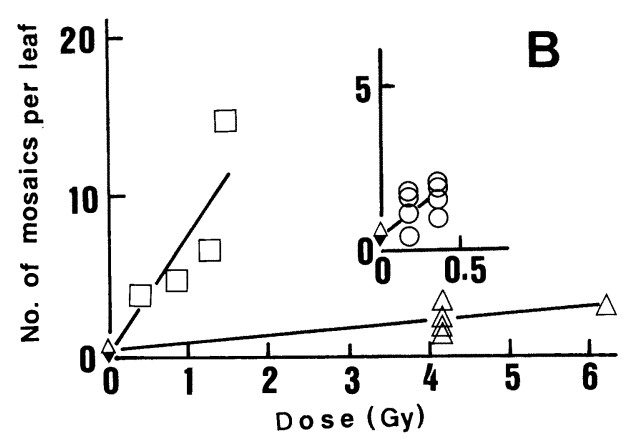

Fig. 1. Frequencies per leaf of three types of mosaics on simple leaves of soybeans plotted against absorbed doses in soybean seed tissue given by $\mathrm{X}$ rays $(\triangle), 14 \mathrm{MeV}$ neutron-gamma mixed radiation ( $\square$ ) and fission neutron-gamma mixed radiation $(\bigcirc)$. Symbol $(\diamond)$ stands for spontaneous frequencies. A, Light-green mosaics on yellow $\left(y_{11} y_{11}\right)$ leaves. The broken line represents a theoretical dose-response curve for fast neutrons; it was constructed using the average of the RBE values experimentally determined for $14 \mathrm{MeV}$ neutrons and fission neutrons given in Table 2. B, Dark-green mosaics on light-green $\left(Y_{11} y_{11}\right)$ leaves. $\mathrm{C}$, Yellow mosaics on light-green $\left(Y_{11} y_{11}\right)$ leaves.

soybean cotyledon tissue), $a$ is spontaneous rate of mosaics and $b$ is induced rate per Gy of mosaics.

The $b$ value for induction by neutron-gamma mixed radiation, $b_{n+g}$, may be approximated by

$$
b_{n+g}=(1-r) b_{g}+r b_{n},
$$

where $r$ is a fraction of the total neutron-gamma dose contributed by neutrons, $b_{g}$ is the induced rate per Gy by gamma rays and $b_{n}$ is the induced rate per Gy by neutrons. Approximating the $b_{g}$ values with observed $b_{x}$ values, i.e., the induced rates by $\mathrm{X}$ rays given in Table 2 , and using the experimental $r$ values of 0.60 and 0.46 for the $14 \mathrm{MeV}$ neutron-gamma mixed radiation and the fission neutrongamma mixed radiation, respectively, we can estimate the $b_{n}$ values by Eq. (4) using the observed $b_{n+g}$ values (Table 2). Ratios of the resultant $b_{n}$ values to $b_{x}$ values are the RBE (relative biological effectiveness) values of neutrons given in 
Table 2. Induced rates of three types of mosaics on simple leaves of soybeans by X rays, 14 $\mathrm{MeV}$ neutron- $\gamma$ mixed radiation and fission neutron $-\gamma$ mixed radiation, and relative biological effectiveness (RBE) of $14 \mathrm{MeV}$ and fission neutrons for induction of the somatic mutations

\begin{tabular}{|c|c|c|c|c|c|c|c|c|}
\hline \multirow{2}{*}{$\begin{array}{l}\text { Genotype } \\
\text { of leaves } \\
\text { studied }\end{array}$} & \multirow{2}{*}{$\begin{array}{l}\text { Type of } \\
\text { induced } \\
\text { mosaics }\end{array}$} & \multicolumn{3}{|c|}{$\begin{array}{l}\text { Induced rate } b \text { of } \\
\text { mosaics/leaf/Gy } \\
\text { by }\end{array}$} & \multicolumn{2}{|c|}{$\begin{array}{l}\text { Estimate for induced } \\
\text { rate }^{a} \text { of } \\
\text { mosaics/leaf/Gy by }\end{array}$} & \multicolumn{2}{|c|}{$\begin{array}{c}\mathrm{RBE} \text { for fast } \\
\text { neutrons }\left(b_{n} / b_{x}\right)\end{array}$} \\
\hline & & $\begin{array}{c}\mathrm{X} \text { rays } \\
b_{x}\end{array}$ & $\begin{array}{c}14 \mathrm{MeV} \\
\text { neutron- } \gamma \\
b_{n+g}\end{array}$ & $\begin{array}{c}\text { Fission } \\
\text { neutron- } \gamma \\
b_{n+g}\end{array}$ & $\begin{array}{c}14 \mathrm{MeV} \\
\text { neutrons } \\
b_{n}\end{array}$ & $\begin{array}{l}\text { Fission } \\
\text { neutrons } \\
b_{n}\end{array}$ & $\begin{array}{l}14 \mathrm{MeV} \\
\text { neutrons }\end{array}$ & $\begin{array}{c}\text { Fission } \\
\text { neutrons }\end{array}$ \\
\hline$y_{11} y_{11}$ & $\begin{array}{l}\text { Light } \\
\text { green }\end{array}$ & $0.80 \pm 0.09$ & $15 \pm 2.5$ & $9.3 \pm 2.1$ & $25 \pm 4.2$ & $19 \pm 4.5$ & $31 \pm 6.3$ & $24 \pm 6.2$ \\
\hline$Y_{11} y_{11}$ & $\begin{array}{l}\text { Dark } \\
\text { green }\end{array}$ & $0.43 \pm 0.08$ & $7.6 \pm 2.4$ & $3.7 \pm 1.1$ & $12 \pm 3.9$ & $7.5 \pm 2.3$ & $29 \pm 11$ & $17 \pm 6.2$ \\
\hline$Y_{11} y_{11}$ & Yellow & $1.0 \pm 0.16$ & $14 \pm 3.5$ & $12 \pm 2.9$ & $22 \pm 6.2$ & $25 \pm 6.7$ & $22 \pm 6.7$ & $25 \pm 7.3$ \\
\hline
\end{tabular}

the last two columns of Table 2 .

Similarity between dark-green mutations in $Y_{11} y_{11}$ plants and light-green mutations in $y_{11} y_{11}$ plants and dissimilarity between dark-green and yellow mutations

We conclude from Table 2 that X-ray induction of light-green mosaics in the $y_{11} y_{11}$ tissue occurred at a rate about twice as high as that of dark-green mosaics in the $Y_{11} y_{11}$ tissue. This result can be explained by the assumption that both the light-green and the dark-green mosaics result from reversion of the $y_{11}$ gene to $Y_{11}$ since the number of the target gene $y_{11}$ in the $y_{11} y_{11}$ tissue is twice as many as that in the $Y_{11} y_{11}$ tissue. If this is the case, however, we must explain the reason why, in the $Y_{11} y_{11}$ tissue, $\mathrm{X}$-ray induction of dark-green mosaics occurred at a rate about half as high as that of yellow mosaics (Table 2; Vig, 1974).

After treatment of $Y_{11} y_{11}$ seeds with Mitomycin C, i.e., a potent inducer of somatic crossing over, dark-green mosaics occurred more frequently than yellow mosaics whereas twin mosaics occurred far more frequently than dark-green mosaics (Vig and Paddock, 1968). Based on these and other results, Vig (1974) and Vig et al. (1976) proposed that yellow mosaics induced in $Y_{11} y_{11}$ plants resulted from the loss of the $Y_{11}$ bearing chromosome fragments whereas light-green mosaics induced in $y_{11} y_{11}$ plants resulted from the point mutations. This proposal is compatible with the findings that in $Y_{11} y_{11}$ plants, yellow mosaics occurred more frequently than dark-green mosaics after $\mathrm{X}$-irradiation, as we assume that darkgreen mosaics are caused by the same reversion mutation that induces light-green mosaics in $y_{11} y_{11}$ plants, and as we know that deletion mutations are induced more frequently by X-irradiation than point mutations (Ishii and Kondo, 1975; Sankaranarayanan, 1982). 


\section{Hypothesis for the nature of the $y_{11}$ gene}

If X-ray induced yellow mosaics in $Y_{11} y_{11}$ plants result from the deletion mutations at the $Y_{11}$ locus, fast neutrons must produce yellow mosaics at a rate much higher than the induced rate by $\mathrm{X}$ rays as previously reported for chlorophyll mutations in wheat and hairless somatic mutations in Arabidopsis (see Kondo, 1964, for review). This was actually the case; $14 \mathrm{MeV}$ neutrons and fission neutrons were, respectively, $22 \pm 7$ and $25 \pm 7$ times more effective for induction of yellow mosaics than $\mathrm{X}$ rays (see the numerical values of $\mathrm{RBE}$ for yellow mosaics in Table 2).

To our surprise, however, RBE values of the two types of neutrons for induction of dark-green mosaics in $Y_{11} y_{11}$ plants and those for induction of light-green mosaics in $y_{11} y_{11}$ plants were close to those for induction of yellow mosaics as seen from Table 2. Therefore, the high RBE values of neutrons strongly suggest that the $y_{11}$ to $Y_{11}$ reversion, which is assumed in this paper as the major cause of both the dark-green and the light-green mosaics, results from deletion mutations.

A simple model to explain these unexpected results is that the $y_{11}$ gene is a complex of the $Y_{11}$ gene with a transposon-like insert that partially suppresses the normal function of the $Y_{11}$ gene. On this assumption, the inserted element is expected to be deleted-reversion process toward a wild-type gene-at a high frequency when the inserted element and/or its neighboring DNA region are damaged by irradiation. Multiple DNA lesions are more frequently induced by fast neutrons than X rays (Leenthouts and Chadwick, 1978).

Our proposal is a working hypothesis for the future study of semi-dominant mutant genes called Xantha that partially suppress the chlorophyll development in plants. These dominant genes are named $X a$ for they produce xanthophyllic phenotypes; they are known at several loci in barley (Prina and Favret, 1988) and tomato (Young and MacArthur, 1947).

We thank the late Dr. T. Fujii for giving us the variety T219 of soybean, T. Yoshida for harvesting soybean, Dr. M. Ikenaga for the use of an X-ray generator, Drs. K. Sumita and J. Yamamoto for the use of a 14-MeV neutron generator, Dr. K. Fujikawa and H. Ryo for their suggestions during the preparation of the manuscript, Y. Aoki and S. Hisanaga for operating the nuclear reactor of Kinki University, K. Morimoto for preparing the manuscript, and finally, but not the least, S. Nakano for the invaluable help in the experiments.

\section{REFERENCES}

Fujii, T. (1981). Mutagenic effect of L-ethionine in soybean and maize. Environ. Expt. Bot. 21, $127-131$.

Fujii, T. (1982). Mutagenicity testing of chemical mutagens in higher plants. In: Environmental Mutagens and Carcinogens, (eds.: T. Sugimura, S. Kondo and H. Takebe), pp. 399-410. University of Tokyo Press, Tokyo. 
Fujii, T., Shizaki, M., Fujiki, H. and Sugimura, T. (1983). Effect of TPA on the mutagenicity of caffeine in the soybean mutation test. Mutat. Res. 110, 263-269.

ICRU (1957). Report of the International Commission on Radiological Units and Measurements (ICRU) 1956, Natl. Bureau of Standards Handbook 62, U.S. Department of Commerce, Washington, D.C.

ICRU (1964). Physical aspects of irradiation. Recommendations of the International Commission on Radiological Units and Measurements (ICRU), Report 10b 1962, Natl. Bureau of Standards Handbook 85, U.S. Department of Commerce, Washington, D.C.

ICRU (1969). Neutron fluence, neutron spectra and kerma. ICRU Report 13, International Commission on Radiation Units and Measurements, Washington, D.C.

Ishii, Y. and Kondo, S. (1975). Comparative analysis of deletion and base-change mutabilities of Escherichia coli $B$ strains differing in DNA repair capacity (wild-type, $u v r A^{-}$, polA- $A^{-}, \operatorname{rec} A^{-}$) by various mutagens. Mutat. Res. 27, 27-44.

Kondo, S. (1964). Variation in mutagenicity and radiation resistance with genome complexity and evolution. Jpn. J. Genet. 39, 176-198.

Leenthouts, H. P. and Chadwick, K. H. (1978). The crucial role of DNA double-strand breaks in cellular radiobiological effects. Adv. Radiat. Biol. 7, 55-101.

Oda, K., Ito, M., Miyake, H., Michijima, M. and Yamamoto, J. (1988). Track formation in CR-39 detector exposed to D-T neutrons. Nuclear Instruments and Methods in Physics Research $\mathbf{B 3 5}$, $50-56$.

Prina, A. R. and Favret, E. A. (1988). Influence of marker genes on the expression of somatic mutations in barley. J. Heredity 79, 371-376.

Randolph, M. L. (1957). Energy deposition in tissue and similar materials by 14.1-MeV neutrons. Radiat. Res. 7, 47-57.

Sankaranarayanan, K. (1982). Genetic effects of ionizing radiation in multicellular eukaryotes and the assessment of genetic radiation hazards in man. Elsevier, Amsterdam.

Sumita, K., Takahashi, A., Iida, T., Yamamoto, J., Imoto, S. and Matsuda, K. (1982). Osaka University $14 \mathrm{MeV}$ intense neutron source and its utilizations for fusion studies (OKTAVIAN program). Proc. 12th Symp. Fusion Technology 1982 1, pp. 675-680.

Vig, B. K. (1973a). Somatic crossing over in Glycine max (L.) Merrill: Effect of some inhibitors of DNA synthesis on the induction of somatic crossing over and point mutations. Genetics 73, 583596.

Vig, B. K. (1973b). Somatic crossing over in Glycine $\max$ (L.) Merrill: Mutagenicity of sodium azide and lack of synergistic effect with caffeine and mitomycin C. Genetics 75, 265-277.

Vig, B. K. (1973c). Mitomycin C induced leaf mosaicism in Glycine max (L.) Merrill in relation to the post germination age of the seed. Theoret. Appl. Genet. 43, 27-30.

Vig, B. K. (1974). Somatic crossing-over in Glycine $\max$ (L.) Merrill: Differential response to ${ }^{3} \mathrm{H}$-emitted $\beta$-particles and ${ }^{60} \mathrm{Co}$ emitted $\gamma$-rays. Radiat. Bot. 14, 127-137.

Vig, B. K. (1975). Soybean (Glycine max): A new test system for study of genetic parameters as affected by environmental mutagens. Mutat. Res. 31, 49-56.

Vig, B. K. (1978). Somatic mosaicism in plants with special reference to somatic crossing over. Environ. Health Perspect. 27, 27-36.

Vig, B. K., Nilan, R. A. and Arenaz, P. (1976). Somatic crossing over in Glycine max (L.) Merrill: Induction of somatic crossing over and specific locus mutations by methyl methanesulfonate. Environ. Exp. Bot. 16, 223-234.

Vig, B. K. and Paddock, E. F. (1968). Alteration by mitomycin C of spot frequencies in soybean leaves. J. Heredity 59, 225-229.

Yamamoto, J., Takahashi, A., Izumi, M. and Sumita, K. (1989). Determination of tritium breeding ratio in a $\mathrm{Pb}-\mathrm{Li}$ spherical blanket by leakage neutron spectra. Fusion Engineering and Design 10, $169-174$. 
Yasubuchi, S., Hoshi, M., Itoh, T., Hisanaga, S., Niwa, T., Miki, R. and Kondo, S. (1989). Dosimetry of fast neutrons in $1 \mathrm{~W}$ nuclear reactor with plastic nuclear-track detectors. Radioisotopes 38, 359-365.

Young, P. A. and MacArthur, J. W. (1947). Horticultural characters of tomatoes. Texas Agric. Expt. Sta. Bul. 698, 1-61.

Weber, C. R. and Weiss, M. G. (1959). Chlorophyll mutant in soybeans provides teaching aid. $J$. Heredity 50, 53-54. 